\title{
TRAUMATIC HEMIPELVECTOMY
}

\author{
H. J. KLASEN, H. J. TEN DUIS
}

From the University Hospital, Groningen

\begin{abstract}
Traumatic hemipelvectomy is rare, and is usually accompanied by injury to the genito-urinary tract and bowel. Recently, there have been an increasing number of reports of patients who have survived this injury, probably as a result of improved early care. We report three such cases and review the literature.

The amputation wound should not be closed initially; early re-exploration to remove any dead tissue is indicated, and this should be repeated as necessary.
\end{abstract}

Only 20 cases of traumatic hemipelvectomy have been reported in the last 20 years, but specific methods of treatment are not usually discussed (McPherson 1960; McLean 1962; Johansson and Olerud 1971; Turnbull 1978; Lipkowitz et al. 1985; Chappel et al. 1986). Since 1974, three patients with traumatic hemipelvectomy have been treated at the University Hospital Groningen, and as a result of this experience we are able to give some details of management and of the underlying principles.

\section{CASE REPORTS}

Case 1. In 1975 a 24-year-old farmer was trapped by his right leg in farm machinery and was in surgical shock on arrival at our department. He had multiple open fractures of the right leg, and no circulation or sensation in this limb. Wounds in the right groin were extensive and contained shreds of muscle tissue. Wounds in the left groin and the left buttock were heavily contaminated with soil. In view of his critical condition, radiographs were taken only of the thorax and pelvis. The chest radiograph was normal; the pelvic films showed right sacro-iliac dislocation and symphysiolysis. The left pubic bone was fractured and the left hip was dislocated.

Immediate surgery was performed under general anaesthesia. Haemostasis was secured, the external iliac

\footnotetext{
H. J. Klasen, MD, Professor of Surgery

H. J. ten Duis, MD, Surgeon

Division of Traumatology, University Hospital Groningen, P.O. Box 30.001, 9700 RB Groningen, The Netherlands.

Correspondence should be sent to Professor H. J. Klasen.

(C) 1989 British Editorial Society of Bone and Joint Surgery $0301-620 \mathrm{X} / 89 / 2049 \$ 2.00$

J Bone Joint Surg [Br] 1989;71-B:291-5.
}

artery and vein being ligated and the wounds thoroughly cleaned. The right leg, attached only by a bridge of skin, was discarded and hemipelvectomy completed. The peritoneum was intact. The bladder was full of urine and was catheterised via the urethra. Both testes had been avulsed from the scrotum. The anorectal region was severely damaged; the anus was missing and shreds of rectum were visible in the wound. The skin of the back had been degloved up to the scapulae.

At laparotomy, no abnormalities were found and a colostomy of the descending colon was performed, the distal loop being closed. Extensive wound debridement included the removal of large amounts of dead muscle and the amputation wound was then closed around a drain. Subsequently, the open dislocation of the left hip was explored through the large wound on the medial side of the leg, and a large amount of soil removed from the joint by prolonged flushing with saline. The dislocation was then reduced. During the operation the patient received 18 units of blood.

Postoperative complications included abscesses which necessitated three exploratory operations. After two months, the urinary catheter was removed, but there was 150 to $175 \mathrm{ml}$ of residual urine. At 14 weeks, persistent fever and pain on hip movement developed, and radiographs showed subchondral decalcification. The hip was explored on suspicion of suppurative arthritis. The femoral head was black and dead, and all the acetabular cartilage had disappeared. After this his temperature returned to normal and the pain subsided.

The patient was transferred to a rehabilitation centre after five months and a hemipelvectomy prosthesis was adapted by adding a long leg brace with a hinge at the hip. Initially, the ankle was fixed to compensate for peroneal nerve palsy but this improved. He eventually 
regained satisfactory mobility. No attempt was made to reconstruct the bowel, and he did not wish to have the distal portion of the colon resected. As a result, he had a mucous fistula in the anal area, but this caused little inconvenience. He wears an appliance for stress incontinence.

At the latest review, 12 years after the accident, the patient was in good physical condition, working full-time as an estate agent, and could walk 300 metres with the prosthesis and two crutches. Radiographs showed complete ankylosis of the left hip in $35^{\circ}$ of flexion and $20^{\circ}$ of abduction; the left sacro-iliac joint also was ankylosed (Fig. 1), but there were no degenerative changes in the spine.

Case 2. In May 1984 a 28-year-old man caught his right leg in a winch and sustained severe traction injuries at the groin. A large wound was continuous with the anus, and the right leg had no sensation, movement or circulation. Radiographs taken during resuscitation showed right sacro-iliac dislocation and symphysiolysis (Fig. 2a). An IVP showed urethral rupture but ultrasound did not show fluid in the abdomen. Angiography showed obstruction of the external iliac artery. Wound exploration under general anaesthetic revealed that the iliac artery and vein and the lumbosacral plexus had been torn through. There was serious bleeding of the presacral venous plexus and the distal rectum had no soft tissue attachment.

A transverse colostomy was performed and the bladder was drained by a suprapubic catheter. The urethral rupture was at the level of the urogenital diaphragm, and, despite severe penile injuries, it was possible to catheterise the bladder via the penis. Gauze tampons were used to control serious bleeding from the presacral area and the symphysiolysis was repaired to assist tamponade. Disarticulation at the hip was performed, and the wound was left open. During the operation the patient received 25 units of blood. Two days later, at re-exploration, the iliopsoas muscle was necrotic and was therefore removed.

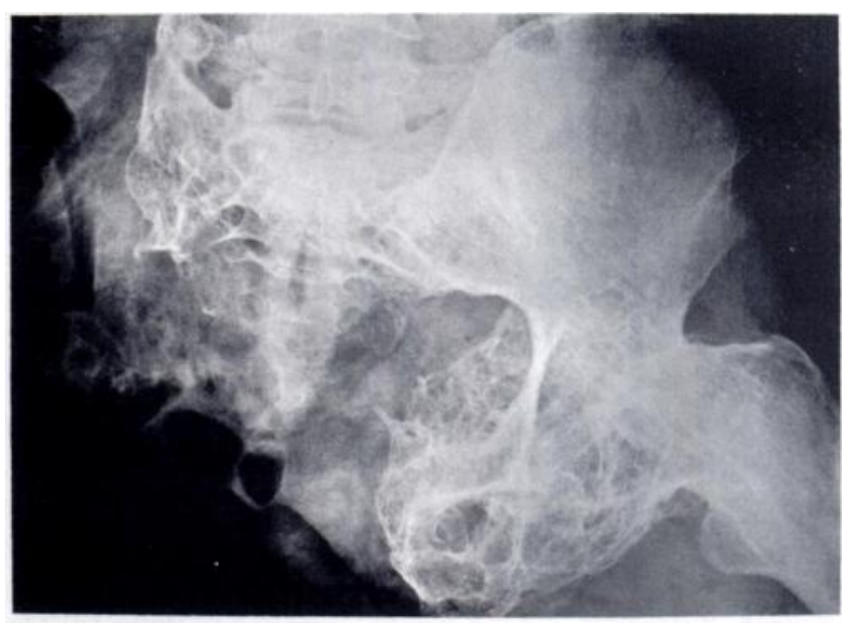

Fig. 1

Case 1. Twelve years after hemipelvectomy. There is ankylosis of the sacro-iliac joint and the hip.

Hemipelvectomy was completed four days after the accident, but again the amputation surface was not closed and daily debridement was continued. Four weeks after hemipelvectomy the skin defects were closed by grafts. Urine leakage at the level of the neck of the

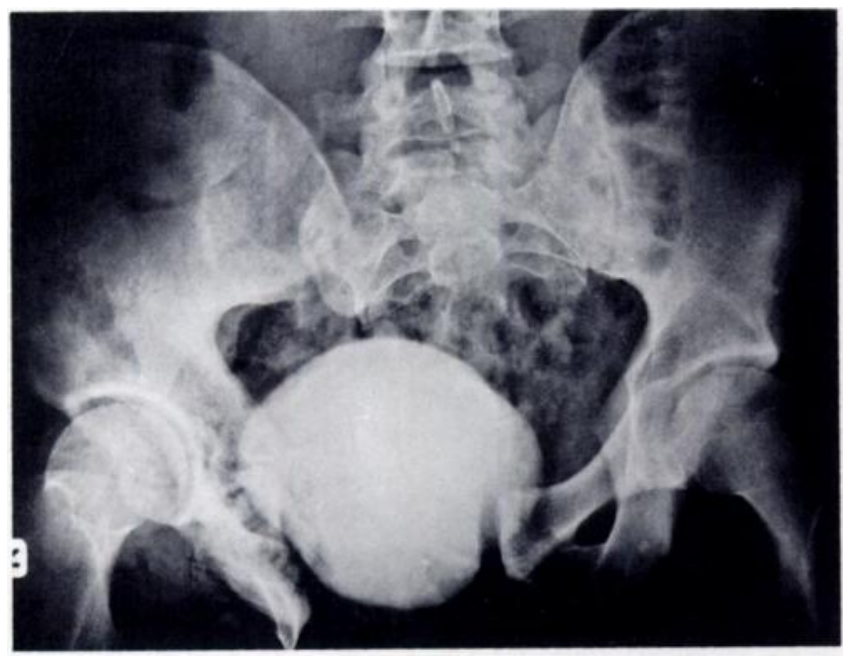

Fig. 2a

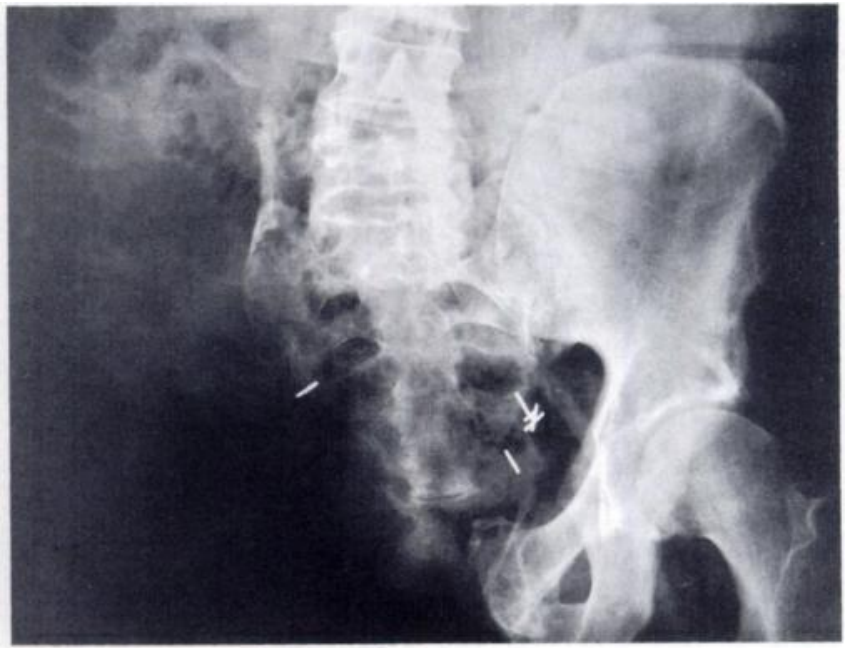

Fig. 2b

Case 2. Figure 2a-On admission incomplete hemipelvectomy with sacro-iliac dislocation and symphysiolysis. There is an acetabular fracture on the left side. Figure $2 b$ - Three years after the accident. There is ectopic bone formation around the sacrum. 
bladder required repair, but the urethra could not be reconstructed.

Ten weeks after injury the patient was discharged to a rehabilitation centre, his wounds having healed. Despite a peroneal nerve palsy, he was mobilised with two crutches. The colostomy was not repaired because it was assumed that he would be incontinent. A hemipelvectomy prosthesis was fitted with some difficulty caused by rapid fluctuations in the patient's weight. The colostomy, which was on the side of the hemipelvectomy, also gave rise to problems.

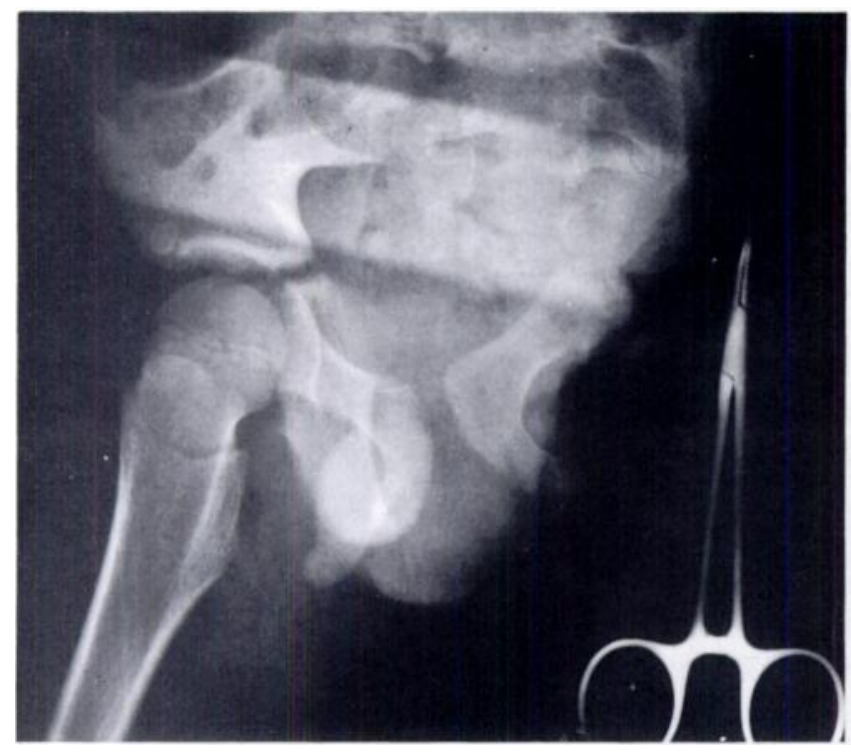

Fig. 3a sacro-iliac joint and the superior and inferior rami of the pubic bone. The IVP was normal and ultrasound did not demonstrate any intraperitoneal fluid. The wound was contaminated with dirt and grease, but the anus was not damaged, and a cuff of skin several centimetres wide remained on the left side. Before the patient was anaesthetised it was established that a good anal reflex was present. The scrotum was intact, but the left testicle was not in its normal position. There was degloving of the skin up to the level of the scapulae.

At exploration the bladder was seen to be filled with

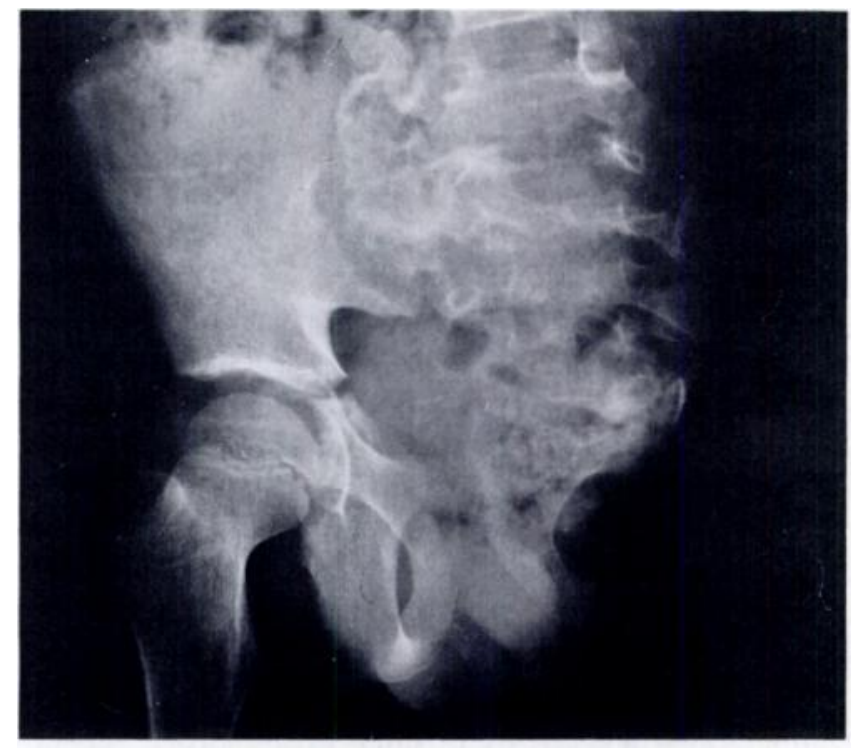

Fig. 3b

Case 3. Figure 3a - The plane of the amputation is through the sacro-iliac joint and the obturator foramen. Figure $3 \mathrm{~b}$ - Appearance one year later.

Six months after the accident, revision of the stump was performed and at 18 months a new colostomy of the sigmoid was opened at a more accessible site and the distal colon resected. At three years, the patient is not coping well with the prosthesis, which he rarely wears; he is unemployed and socially isolated. This lack of adjustment and adaption may, however, be largely due to a serious brain injury he suffered at the age of 14 . A pelvic radiograph shows some ectopic bone formation around the sacrum (Fig. 2b).

Case 3. A seven-year-old boy seriously injured his left leg in a winch while playing in a shipyard and was brought $80 \mathrm{~km}$ to our hospital. He was in surgical shock with severe injuries and his left leg had been completely avulsed (Fig. 3a). Resuscitation was started and the external iliac artery and vein were clamped. A chest radiograph was normal and the pelvic radiograph showed that the plane of separation was through the urine, and the urethra and peritoneum were intact. Laparotomy was not performed. Damaged muscle was removed, the loose skin on the back was incised to provide drainage and the external iliac artery and vein were ligated. Nerves had retracted and could not be identified.

The wound at the amputation site was left open, but covered with mesh grafts taken from the amputated leg. Two days later the first wound inspection was performed under anaesthesia; no dead tissue was found, and the wound was partially closed. The urinary catheter was removed on the fifth day; spontaneous urination was possible. At seven days, the remaining skin grafts were removed because complete wound closure was possible. Defaecation was normal. Two weeks after the accident the patient was mobilised on crutches and when discharged from hospital five weeks after the injury he was fully mobile. Two months after the accident he 
returned to school, walking with two crutches. A prosthesis with a pelvic girdle and a knee hinge on a lightweight frame was provided, but this was worn only during the morning school hours because it restricted his activities. For play he was allowed to leave off the prosthesis, partly because he lives on the waterfront and had often fallen in.

\section{DISCUSSION}

Few people have survived a traumatic hemipelvectomy, only 20 having been described in the literature. Our experience with three patients corresponds with that in the other reports. Twenty of all 23 patients were male; 16 were the victims of a traffic accident; the other seven were injured in winches (4), combine harvesters (2) or by a roller belt. Most were between 20 and 25 years of age (range seven to 32 years). The number of reported survivors has increased during the last 20 years, probably as a result of more efficient transport to hospital and improved treatment of shock. The use of pneumatic antishock trousers has been reported only once (Danisi and Stromberg 1985). In 13 of the 23 patients the leg had been completely amputated, while in four it was connected only by a bridge of skin.

Surgical treatment of these patients should aim, in the first place, to save life. In those who still have some connecting structures, the hemipelvectomy should be completed, since haemostasis and adequate debridement are then easier to achieve, and there are likely to be fewer complications. This was illustrated in our Case 2, where haemostasis might have been achieved more quickly if hemipelvectomy had been completed at the first stage. In patients with large wounds and no sensation, movement or circulation in the leg, hemipelvectomy is probably inevitable.

Before operation it is important to try to define the precise nature of the injuries by appropriate investigations; this may necessitate a compromise between the need to operate quickly for the bleeding and the delay for special examinations. In modern, wellorganised Accident and Emergency departments resuscitation and diagnostic procedures can usually be carried out concurrently. The most essential investigations are radiographs of the chest and pelvis, and an IVP and retrograde examination of the urinary passages also have high priority because injuries of the urinary system are frequent, being seen in 19 of the 23 reported patients (Table I). Urethral injuries at the level of the prostate and the membranous urethra were common. Good drainage is needed, usually by a suprapubic urinary catheter, and a damaged urethra may need splinting with a catheter. Immediate reconstruction should not be attempted.

Associated injuries were present in 15 of the 23 patients (Table II), but only one had intraperitoneal damage (Moore et al. 1987). There were other pelvic injuries in seven of the 23 patients (Orcutt et al. 1974; Meester and Myerley 1975; Maull, Sachatello and Ernst 1977; Evans and Foss 1984; Danisi and Stromberg 1985; Chappel et al. 1986); 18 had some damage to the anal region, and 20 had a colostomy. This was nearly always definitive; it was closed in only three patients, including two who had had no anal injury (Wade and Macksood 1965; Pálvölgyi 1969; Siemens and Flint 1977). Colostomy is sometimes indicated to prevent wound contamination with faeces. The position of the colostomy

Table I. Genito-urinary injuries in 19 of 23 cases of traumatic hemipelvectomy

\begin{tabular}{llll}
\hline Urethra & 9 & Avulsion of penis & 2 \\
Scrotal avulsion & 6 & Corpus cavernosum & 2 \\
Avulsion of testes & 5 & Vagina & 2 \\
Prostate & 3 & Bladder & 1 \\
Dislocation of testes & 2 & Ureter & 1 \\
\hline
\end{tabular}

should take account of the eventual prosthesis; it may be better on the contralateral side. Again, immediate bowel reconstruction should never be performed.

An open amputation wound allows good drainage and makes re-exploration easier; this is agreed in most recent reports, but it may be useful to cover the wounds with skin grafts from the amputated leg (Oppenheim, Tricker and Smith 1977; Evans and Foss 1984). There is nearly always more dead muscle than expected, especially in the long muscles of the back, the latissimus dorsi, the retroperitoneal muscles, iliopsoas and quadratus

\begin{tabular}{lccr}
$\begin{array}{l}\text { Table II. Associated injuries in } \\
\text { traumatic hemipelvectomy }\end{array}$ & & \\
\hline Arm & 7 & Thorax & 23 cases of \\
Other side of pelvis & 6 & Spinal column & 2 \\
Head & 3 & Intraperitoneal & 1 \\
\hline
\end{tabular}

lumborum. Necrosis of iliopsoas, probably from traction injury, may cause problems (Rodriguez-Morales et al. 1983; Danisi and Stromberg 1985). Many complications can be prevented by routine early re-exploration under anaesthesia.

The plane of a traumatic hemipelvectomy usually runs through the sacro-iliac joint and the symphysis pubis but in our third patient it ran through the obturator foramen. This has not been reported before, but the extra piece of pubic bone is useful in acting as a support for the prosthesis. Not all the patients can or will wear a 
prosthesis after hemipelvectomy and some, especially children, are more mobile on crutches. Our first patient wears his prosthesis all day, the second cannot manage it well and prefers a wheelchair. Our third patient, the little boy, prefers not to use his prosthesis.

No benefits in any form have been received or will be received from a commercial party related directly or indirectly to the subject of this article.

\section{REFERENCES}

Chappel R, Herregods P, Gevaert M, Mortier G. Traumatic hemipelvectomy, a case report. Acta Belg Med Phys 1986;9:79-83.

Danisi FJ, Stromberg BV. Traumatic hemipelvectomy. Plast Reconstr Surg 1985;76:945-7.

Evans RN Jr, Foss FE. Traumatic hemipelvectomy in combination with traumatic amputation of an upper extremity. J Trauma $1984 ; 24: 342-5$.

Johansson $\mathbf{H}$, Olerud $\mathrm{S}$. Traumatic hemipelvectomy in a ten-year-old boy. J Bone Joint Surg [Am] 1971;53-A :170-2.

Lipkowitz G, Phillips T, Coren C, et al. Hemipelvectomy, a lifesaving operation in severe open pelvic injury in childhood. $J$ Trauma $1985 ; 25: 823-7$.
Maull KI, Sachatello CR, Emst CB. The deep perineal laceration - an injury frequently associated with open pelvic fractures: a need for aggressive surgical management : a report of 12 cases and review of the literature. J Trauma 1977;17:685-96.

McLean EM. Avulsion of the hindquarter. $J$ Bone Joint Surg [Br] 1962;44-B:384-5.

McPherson JH Jr. Traumatic hindquarter amputation. J Med Assoc Ga 1960;49:494-5.

Meester GL, Myerley WH. Traumatic hemipelvectomy: case report and literature review. J Trauma 1975;15:541-5.

Moore WM, Brown JJ, Haynes JL, Viamontes L. Traumatic hemipelvectomy. J Trauma 1987;27:570-2.

Oppenheim WL, Tricker J, Smith RB. Traumatic hemipelvectomy - the tenth survivor: a case report and review of the literature. Injury 1977-1978;9:307-12.

Orcutt TW, Emerson CW Jr, Rhamy RK, Cocke W Jr. Reconstruction and rehabilitation following traumatic hemipelvectomy and brachial plexus injury. J Trauma 1974;14:695-704.

Pálvölgyi L. Traumás hemipelvektomia. Orv Hetil 1969:110:970-3.

Rodriguez-Morales G, Phillips T, Conn AK, Cox EF. Traumatic hemipelvectomy: report of two survivors and review. J Trauma 1983;23:615-20.

Siemens R, Flint LM Jr. Traumatic hemipelvectomy: a case report. $J$ Trauma 1977;17:245-7.

Turnbull H. A case of traumatic hindquarter amputation. Foreword by Wyndham NR. Br J Surg 1978;65:390-2.

Wade FV, Macksood WA. Traumatic hemipelvectomy: a report of two cases with rectal involvement. J Trauma 1965;5:554-62. 